\title{
Change in PMI During Neoadjuvant Therapy Is a Predictive Prognostic Marker in Rectal Cancer
}

\author{
TATSUNARI FUKUOKA ${ }^{1}$, KIYOSHI MAEDA ${ }^{2}$, HISASHI NAGAHARA ${ }^{1}$, MASATSUNE SHIBUTANI ${ }^{1}$, \\ YASUHITO ISEKI ${ }^{1}$, SHINJI MATSUTANI ${ }^{1}$, KOSEI HIRAKAWA ${ }^{1}$ and MASAICHI OHIRA ${ }^{1}$ \\ ${ }^{1}$ Department of Gastroenterological Surgery, Osaka City University Graduate School of Medicine, Osaka, Japan; \\ ${ }^{2}$ Department of Gastroenterological Surgery, Osaka City General Hospital, Osaka, Japan
}

\begin{abstract}
Background/Aim: Neoadjuvant therapy is often administered to patients with locally advanced rectal cancer (LARC). The aim of this study was to investigate the correlation between the change in the psoas muscle index (PMI) during neoadjuvant therapy and the prognosis of LARC patients. Patients and Methods: Forty-seven patients who underwent potentially curative surgery for LARC with neoadjuvant therapy were enrolled in this study. We evaluated the relationship between the prognosis and clinicopathological factors, including the prognostic value of a change in the PMI. Results: A $>10 \%$ decrease in the PMI value was observed in 15 of the 47 patients. A $>10 \%$ decrease in the PMI value was associated with shorter OS and RFS compared to patients who did not show a $>10 \%$ decrease in their PMI. The decrease in PMI after neoadjuvant therapy was an independent negative prognostic factor for patients undergoing neoadjuvant therapy for LARC. Conclusion: A decrease in PMI after neoadjuvant therapy might predict a poor prognosis in LARC patients undergoing neoadjuvant therapy.
\end{abstract}

Colorectal cancer (CRC) is the first most commonly diagnosed cancer in Japan. Rectal cancer (RC) is the seventh leading cause of cancer death, with approximately 46,000 new cases and nearly 15,000 deaths in Japan in 2014 (1). Recently, there have been remarkable advances in RC treatment. Neoadjuvant chemoradiotherapy (NACRT) has been established as the standard treatment for locally advanced RC in most parts of Europe and the United States $(2,3)$, while neoadjuvant chemotherapy without radiation (NAC) is a feasible treatment option for locally advanced RC

Correspondence to: Kiyoshi Maeda, MD, 2-13-22 Miyakojimahondori Miyakojima-ku, Osaka 534-0021, Japan. Tel: +81 669291221, Fax: +81 669290886, e-mail: m1378386@med.osakacu.ac.jp

Key Words: Psoas muscle index, rectal cancer, neoadjuvant therapy.
(4). These treatments reduce local recurrence; however, they do not dramatically improve the overall survival (OS) rate. Some patients develop recurrent disease, even if they undergo combined therapy for RC. Furthermore, the indications for postoperative adjuvant chemotherapy remain controversial. Although the TNM classification and histological response are very important prognostic markers, they are not sufficient, and it is necessary to preoperatively predict recurrence and the prognosis after surgery in order to establish the indications for postoperative adjuvant therapy.

In previous studies, the nutritional status has been shown to affect perioperative surgical outcomes, such as complication rates. Furthermore, sarcopenia is associated with a poorer prognosis in patients with pancreatic cancer, gastric cancer, bladder cancer, and hepatocellular carcinoma (5-9). Miyamoto et al. have reported that a decrease in the skeletal muscle index due to the administration of chemotherapy was associated with a poor prognosis in patients with unresectable CRC (10).

The aim of this study was to investigate whether or not the change in the psoas muscle index (PMI; an index of the skeletal muscle mass) due to neoadjuvant therapy could be used to predict the prognosis of RC patients who receive neoadjuvant therapy.

\section{Patients and Methods}

We retrospectively reviewed the data of consecutive RC patients who underwent primary tumor resection after neoadjuvant therapy (NAC or NACRT) at Osaka City University from January 2010 to December 2016. We performed neoadjuvant therapy for patients with pathologically-confirmed rectal adenocarcinoma when the depth of tumor invasion was beyond the outer border of the proper muscle or lymph node involvement $(\mathrm{cN}+)$ was detected on computed tomography, according to National Comprehensive Cancer Network $(\mathrm{NCCN})$ and previous reports $(11,12)$. The exclusion criteria for this study were distant metastasis and a history of malignancies other than RC. Regarding the neoadjuvant therapy regimen, the physician in charge selected NAC or NACRT with consideration of the preoperative diagnosis and background of the patient. 
Table I. Clinicopathologic characteristics of 47 rectal cancer patients with neoadjuvant therapy.

\begin{tabular}{|c|c|}
\hline Clinicopathologic features & $\mathrm{n}=47$ \\
\hline \multicolumn{2}{|l|}{ Gender } \\
\hline Female & 12 \\
\hline Male & 35 \\
\hline \multicolumn{2}{|l|}{ Age (years) } \\
\hline Median & 66 \\
\hline Range & $27-88$ \\
\hline \multicolumn{2}{|l|}{ Location of tumor } \\
\hline Rs & 3 \\
\hline $\mathrm{Ra}$ & 9 \\
\hline $\mathrm{Rb}$ & 35 \\
\hline \multicolumn{2}{|l|}{ Neoadjuvant therapy } \\
\hline \multicolumn{2}{|l|}{ Chemotherapy } \\
\hline mFOLFOX6 & 4 \\
\hline XELOX & 15 \\
\hline XELOX+Cetuximab & 1 \\
\hline \multicolumn{2}{|l|}{ Chemoradiotherapy } \\
\hline Xeloda & 27 \\
\hline \multicolumn{2}{|l|}{ Chemotherapeutic response } \\
\hline $\mathrm{CR}$ & 0 \\
\hline PR & 38 \\
\hline $\mathrm{SD}$ & 6 \\
\hline $\mathrm{PD}$ & 3 \\
\hline \multicolumn{2}{|l|}{ Depth of tumor invasion } \\
\hline $\mathrm{CR}$ or $\mathrm{T} 1$ & 8 \\
\hline $\mathrm{T} 2$ & 11 \\
\hline $\mathrm{T} 3$ & 21 \\
\hline $\mathrm{T} 4 \mathrm{a}$ & 5 \\
\hline $\mathrm{T} 4 \mathrm{~b}$ & 2 \\
\hline \multicolumn{2}{|l|}{ Lymph node metastasis } \\
\hline Negative & 32 \\
\hline Positive & 15 \\
\hline \multicolumn{2}{|l|}{ Stage } \\
\hline $\mathrm{CR}$ or I & 17 \\
\hline II & 15 \\
\hline III & 15 \\
\hline \multicolumn{2}{|l|}{ Procedure } \\
\hline Abdominoperineal resection & 18 \\
\hline Low anterior resection & 27 \\
\hline High anterior resection & 2 \\
\hline \multicolumn{2}{|l|}{ Adjuvant chemotherapy } \\
\hline Oxaliplatin base doublet & 18 \\
\hline Oral only & 16 \\
\hline None & 13 \\
\hline
\end{tabular}

Forty-seven patients who underwent potentially R0 surgery for locally advanced RC with NAC or NACRT were enrolled in the present study. Radiotherapy was performed once (1.8 or 2.0 Gy) daily to reach a total dose of $50.4 \mathrm{~Gy}$. Capecitabine $\left(825-900 \mathrm{mg} / \mathrm{m}^{2}\right)$ was the only chemotherapy agent administered concurrently with RT. Capecitabine was simultaneously given with RT on weekdays, followed by a two-day rest interval on weekends. This cycle was repeated during irradiation. The chemotherapy agents that were administered for NAC were capecitabine + oxaliplatin (CapeOx), capecitabine + oxaliplatin + cetuximab (CapeOx + cetuximab), or modified FOLFOX6.

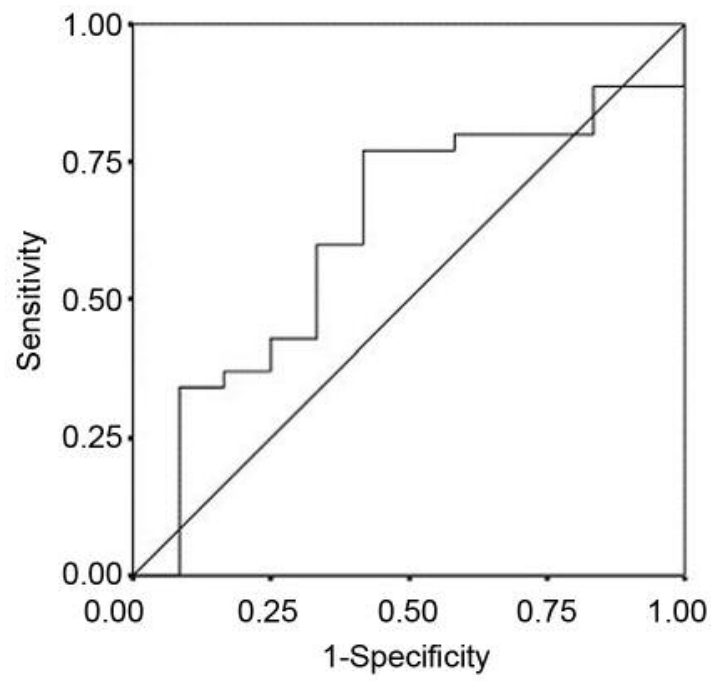

Figure 1. Receiver operating characteristic curve analysis of the changing rate of PMI value. Area under the curve $=0.621,95 \%$ Confidence interval $=0.438-0.805, p=0.213$.

Resected specimens were pathologically classified according to the UICC TNM classification of malignant tumors, version 7 (13). Pathologists evaluated the tumor pathological response according to the Japanese definition (14): Grade 0, no response; Grade 1, necrosis and degeneration of cancer cells ( $<2 / 3$ of tumor cells); Grade 2, significant degeneration, necrosis, fusion, disappearance in more than 2/3 tumor cells; and Grade 3, complete response, extensive degeneration and replacement by granulomatous or fibrous tissue. Postoperative complications were categorized according to the Clavien-Dindo Classification (CDC) (15). We performed adjuvant chemotherapy after the operation at the request of the physician. Oxaliplatin doublet chemotherapy was performed in 18 cases, while oral anticancer agents were provided only in 16 cases. We also followed the patients clinically to monitor the clinical outcomes. All patients underwent regular physical examinations and blood tests, and demographic, pathologic, and outcome data were collected for each patient. The median follow-up period of these patients was 24.1 months (range $=4-85$ months).

PMI. We performed computed tomography before and after neoadjuvant therapy in order to evaluate the effects of neoadjuvant therapy. We calculated the PMI $\left(\mathrm{cm}^{2} / \mathrm{m}^{2}\right)$ before (pre-PMI) and after neoadjuvant therapy (post-PMI). The bilateral psoas muscle area $\left(\mathrm{cm}^{2}\right) / 2$ was calculated at the level of the navel from computed tomography images by a single investigator who was blinded to the patient outcomes (5). To normalize the PMI for body size, the psoas muscle area was divided by the square of the body height $\left(\mathrm{m}^{2}\right)$. We subtracted the pre-PMI from the post-PMI. These values were then divided by the pre-PMI and multiplied by 100 to determine the rate of change in the PMI.

Ethical considerations. This study was approved by the Osaka City University ethics committee. Informed consent was obtained from all patients. 
Table II. Association between the extent of PMI and clinicopathological and surgical factors.

\begin{tabular}{|c|c|c|c|}
\hline \multirow[t]{2}{*}{ Factor } & \multicolumn{2}{|c|}{ PMI } & \multirow[b]{2}{*}{$p$-Value } \\
\hline & $\begin{array}{c}>10 \% \\
\text { decrease } \\
n=15\end{array}$ & $\begin{array}{c}\text { Not }>10 \% \\
\text { decrease } \\
n=32\end{array}$ & \\
\hline \multicolumn{4}{|l|}{ Age } \\
\hline$<70$ & $10(31.3 \%)$ & $22(68.8 \%)$ & \multirow[t]{2}{*}{1.000} \\
\hline$\geq 70$ & $5(33.3 \%)$ & $10(66.7 \%)$ & \\
\hline \multicolumn{4}{|l|}{ Gender } \\
\hline Female & $5(41.7 \%)$ & $7(58.7 \%)$ & \multirow[t]{2}{*}{0.481} \\
\hline Male & $10(28.6 \%)$ & $25(71.4 \%)$ & \\
\hline \multicolumn{4}{|c|}{ Body weight loss } \\
\hline Positive & $9(42.9 \%)$ & $12(57.1 \%)$ & \multirow[t]{2}{*}{0.221} \\
\hline Negative & $6(23.1 \%)$ & $20(76.9 \%)$ & \\
\hline \multicolumn{4}{|c|}{ Diabetes mellitus } \\
\hline Positive & $1(50.0 \%)$ & $1(50.0 \%)$ & \multirow[t]{2}{*}{0.541} \\
\hline Negative & $14(31.1 \%)$ & $31(68.9 \%)$ & \\
\hline \multicolumn{4}{|c|}{ Neoadjuvant therapy } \\
\hline NAC & $7(35.0 \%)$ & $13(65.0 \%)$ & \multirow[t]{2}{*}{0.758} \\
\hline NACRT & $8(29.6 \%)$ & $19(70.4 \%)$ & \\
\hline \multicolumn{4}{|c|}{ PNI (pre-Neoadjuvant therapy) } \\
\hline$<45$ & $9(29.0 \%)$ & $22(71.0 \%)$ & \multirow[t]{2}{*}{0.742} \\
\hline$\geq 45$ & $6(37.5 \%)$ & $10(62.5 \%)$ & \\
\hline \multicolumn{4}{|c|}{ GPS (pre-neoadjuvant therapy) } \\
\hline 0 point & $11(30.6 \%)$ & $25(69.4 \%)$ & \multirow[t]{2}{*}{0.725} \\
\hline $1 \sim 2$ points & $4(36.4 \%)$ & $7(63.6 \%)$ & \\
\hline \multicolumn{4}{|c|}{ PNI (post-neoadjuvant therapy) } \\
\hline$<45$ & $5(27.8 \%)$ & $13(72.2 \%)$ & \multirow[t]{2}{*}{0.504} \\
\hline$\geq 45$ & $9(42.9 \%)$ & $12(57.1 \%)$ & \\
\hline \multicolumn{4}{|c|}{ GPS (post-neoadjuvant therapy) } \\
\hline 0 point & $9(26.5 \%)$ & $25(73.5 \%)$ & \multirow[t]{2}{*}{0.165} \\
\hline $1 \sim 2$ points & $6(50.0 \%)$ & $6(50.0 \%)$ & \\
\hline \multicolumn{4}{|c|}{ Response of NAC/NACRT } \\
\hline CR, PR & $9(23.7 \%)$ & $29(76.3 \%)$ & \multirow[t]{2}{*}{0.021} \\
\hline $\mathrm{SD}, \mathrm{PD}$ & $6(66.7 \%)$ & $3(33.3 \%)$ & \\
\hline \multicolumn{4}{|c|}{ Response of NAC/NACRT } \\
\hline $\mathrm{CR}, \mathrm{PR}, \mathrm{SD}$ & $13(29.5 \%)$ & $31(70.5 \%)$ & \multirow[t]{2}{*}{0.235} \\
\hline $\mathrm{PD}$ & $2(66.7 \%)$ & $1(33.3 \%)$ & \\
\hline \multicolumn{4}{|l|}{ Adjuvant } \\
\hline Absent & $5(38.5 \%)$ & $8(61.5 \%)$ & \multirow[t]{2}{*}{0.728} \\
\hline Present & $10(29.4 \%)$ & $24(70.6 \%)$ & \\
\hline
\end{tabular}

Statistical analysis. A receiver operating characteristic (ROC) curve was used to determine an appropriate cut-off value. All patients were classified into two groups according to the rate of PMI change. The $\chi^{2}$ test and Fisher's exact test were performed to determine the significance of differences in the rate of PMI change and the associated clinicopathological factors. Survival curves were constructed using the Kaplan-Meier method and compared using a log-rank test. The influence of each prognostic factor on the patient's survival was evaluated using a Cox regression analysis. $p$-Values of $<0.05$ were considered to indicate a statistically significant difference. All of the analyses were performed using the SPSS software program (SPSS Japan, Tokyo, Japan).

\begin{tabular}{|c|c|c|c|}
\hline \multirow[t]{2}{*}{ Factor } & \multicolumn{2}{|c|}{ PMI } & \multirow[b]{2}{*}{$p$-Value } \\
\hline & $\begin{array}{c}>10 \% \\
\text { decrease } \\
n=15\end{array}$ & $\begin{array}{c}\text { Not }>10 \% \\
\text { decrease } \\
n=32\end{array}$ & \\
\hline \multicolumn{4}{|l|}{ Adjuvant (doublet) } \\
\hline Absent & $8(27.6 \%)$ & $21(72.4 \%)$ & 0.524 \\
\hline Present & $7(38.9 \%)$ & $11(61.1 \%)$ & \\
\hline \multicolumn{4}{|l|}{ Adverse event } \\
\hline Absent & $2(16.7 \%)$ & $10(83.3 \%)$ & 0.133 \\
\hline Present & $13(37.1 \%)$ & $22(62.9 \%$ & \\
\hline \multicolumn{4}{|l|}{ Operative procedure } \\
\hline Laparotomy & $5(29.4 \%)$ & $12(70.6 \%)$ & 1.000 \\
\hline Laparoscopic resection & $10(33.3 \%)$ & $20(66.7 \%)$ & \\
\hline \multicolumn{4}{|l|}{ Tumor size } \\
\hline Size $<30$ & $4(25.0 \%)$ & $12(75.0 \%)$ & 0.505 \\
\hline Size $\geq 30$ & $10(38.5 \%)$ & $16(61.5 \%)$ & \\
\hline \multicolumn{4}{|l|}{$\mathrm{T}$ category } \\
\hline T0-2 & $4(21.1 \%)$ & $15(78.9 \%)$ & 0.220 \\
\hline $\mathrm{T} 3 / \mathrm{T} 4$ & $11(39.3 \%)$ & $17(60.7 \%)$ & \\
\hline \multicolumn{4}{|l|}{ Lymph node metastasis } \\
\hline Negative & $8(25.8 \%)$ & $23(74.2 \%)$ & 0.322 \\
\hline Positive & $7(43.8 \%)$ & $9(56.2 \%)$ & \\
\hline \multicolumn{4}{|l|}{ Pathological } \\
\hline Grade $0-1$ & $9(30.0 \%)$ & $21(70.0 \%)$ & 0.753 \\
\hline Grade 2-3 & $6(35.3 \%)$ & $11(64.7 \%)$ & \\
\hline \multicolumn{4}{|l|}{ Intraoperative blood loss } \\
\hline$<300 \mathrm{ml}$ & $9(30.0 \%)$ & $21(70.0 \%)$ & 0.753 \\
\hline$\geq 300 \mathrm{ml}$ & $6(35.3 \%)$ & $11(64.7 \%)$ & \\
\hline \multicolumn{4}{|l|}{ Operation time } \\
\hline$<300 \mathrm{~min}$ & $11(37.9 \%)$ & $18(62.1 \%)$ & 0.343 \\
\hline$\geq 300 \mathrm{~min}$ & $4(22.2 \%)$ & $14(77.8 \%)$ & \\
\hline \multicolumn{4}{|l|}{ Complication all CD } \\
\hline Positive & $11(42.3 \%)$ & $15(57.7 \%)$ & 0.121 \\
\hline Negative & $4(19.0 \%)$ & $17(81.0 \%)$ & \\
\hline \multicolumn{4}{|l|}{ Complication $\mathrm{CD} 3 \mathrm{a}$ over } \\
\hline $3 a \sim$ & $4(80.0 \%)$ & $1(20.0 \%)$ & 0.030 \\
\hline $0 \sim 2$ & $11(26.2 \%)$ & $31(73.8 \%)$ & \\
\hline
\end{tabular}

\section{Results}

The patient characteristics are presented in Table I. The study population included 35 men and 12 women, and median patient age at the time of the initial surgery was 66 years (range $=27-88$ years). The distribution of the location of tumor was as follows: upper rectum $(n=3)$, middle rectum $(n=9)$, and lower rectum $(n=35)$. These three parts were defined from the anal verge as follows: lower rectum, 0 to $6 \mathrm{~cm}$; middle rectum, 7 to $11 \mathrm{~cm}$; upper rectum, 12 to 15 $\mathrm{cm}(16,17)$. The chemotherapeutic responses were classified as follows: complete response (CR), $\mathrm{n}=0$; partial response $(P R), n=38$; stable disease $(S D), n=6$; and progressive disease (PD), $n=3$, according to the response 


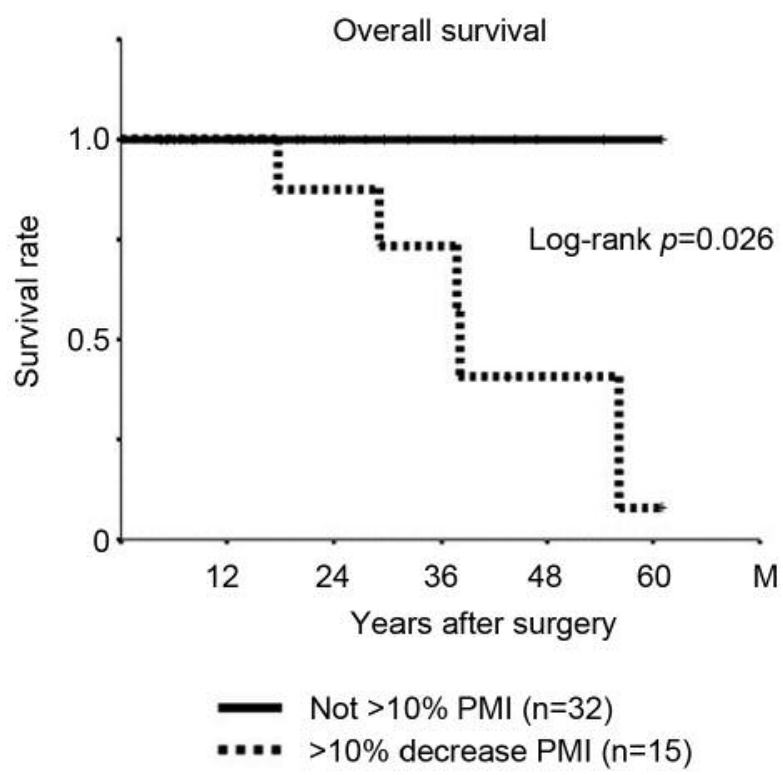

Figure 2. Overall survival of patients. The Kaplan-Meier survival curve of the 47 rectal carcinoma patients with neoadjuvant therapy. The overall survival of patients with a $>10 \%$ decrease in the PMI was significantly worse than the patients with not a $>10 \%$ decrease in their PMI value (Log-rank; $p=0.026)$.

evaluation criteria in solid tumors (RESIST) (18). The response rate was $80.9 \%$, and the disease control rate was 93.6\%. Side effects of NAC or NACRT were estimated in accordance with the Common Terminology Criteria for AEs (CTCAE) v.4.0, Japanese Clinical Oncology Group (JCOG) version. Adverse events were leukopenia (grade $1, \mathrm{n}=3$; grade 2, $n=4$ ), thrombocytopenia (grade $1, n=4$; grade 2 , $\mathrm{n}=5$ ), diarrhea (grade $1, \mathrm{n}=9$; grade $2, \mathrm{n}=2$; grade $3, \mathrm{n}=1$ ), peripheral neuropathy (grade $1, \mathrm{n}=9$; grade $2, \mathrm{n}=1$; grade 3 , $\mathrm{n}=1$ ), appetite loss (grade $1, \mathrm{n}=7$; grade $3, \mathrm{n}=1$ ). Adverse event cases were observed in 25 cases.

The rate of change of the PMI. The mean pre-neoadjuvant PMI value was $325.4 \mathrm{~cm}^{2} / \mathrm{m}^{2}$ (range $\left.=146.7-696.1 \mathrm{~cm}^{2} / \mathrm{m}^{2}\right)$, and the mean post-neoadjuvant PMI value was $313.0 \mathrm{~cm}^{2} / \mathrm{m}^{2}$ (range $=110.5-722.3 \mathrm{~cm}^{2} / \mathrm{m}^{2}$ ). The mean rate of change in the PMI was $-4.3 \%$ (range $=-24.8 \%-25.2 \%$ ). We used the rate of change of the PMI (a continuous variable) as the test variable and the relapse-free survival (RFS) as the state variable. We found that the appropriate cut-off value for the change in the PMI value was $-10 \%$ (sensitivity, $0.771 \%$; specificity, $0.583 \%$ ) using the ROC curve (Figure 1). We set $-10 \%$ as the cut-off value and classified patients according to the presence or absence of a $>10 \%$ decrease in the PMI.

The correlation between the change in the PMI and clinicopathological and surgical factors. A $>10 \%$ decrease

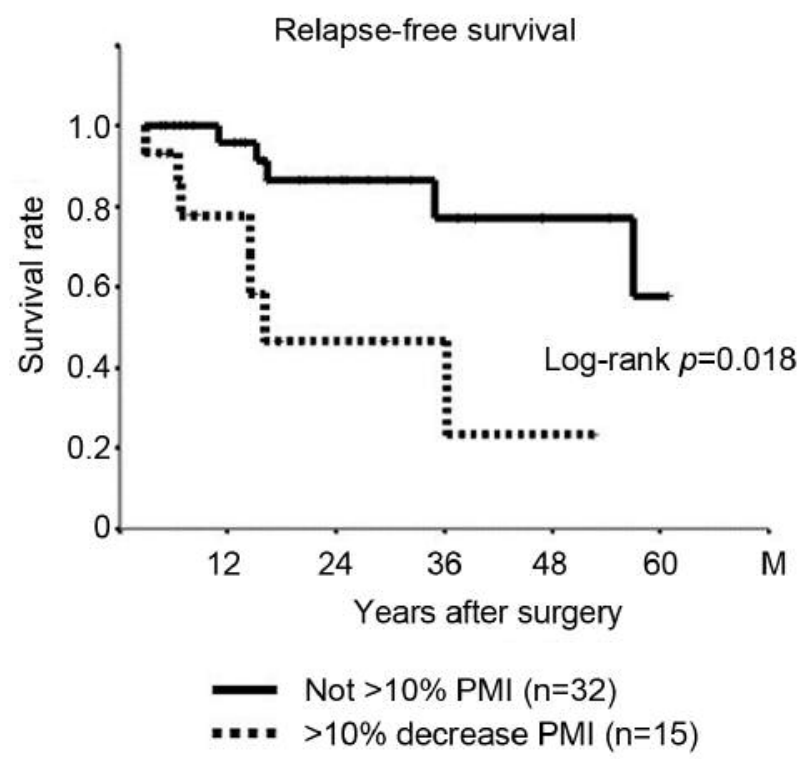

Figure 3. Relapse-free survival of patients. The Kaplan-Meier survival curve of the 47 rectal carcinoma patients with neoadjuvant therapy. The relapse-free survival of patients with $a>10 \%$ decrease in the PMI was significantly worse than the patients with not a $>10 \%$ decrease in their PMI value (Log-rank; $p=0.018)$.

in the PMI was observed in 15 of the 47 patients (32\%). Table II shows the relationship between the decrease in the PMI and clinicopathological factors. A $>10 \%$ decrease in the PMI was associated with severe postoperative complications (CDC $>3 \mathrm{a} ; p=0.030)$ but not with sex $(p=0.481)$, body weight loss $(p=0.211)$, age $(p=1.00)$, neoadjuvant therapy $(p=0.758)$, T stage as depth of tumor invasion $(p=0.220)$, lymph node metastasis $(p=0.322)$, tumor size $(p=0.505)$, pathological grade $(p=0.753)$, adjuvant therapy $(p=0.728)$, adjuvant therapy (doublet) $(p=0.524)$, adverse event of neoadjuvant therapy $(p=0.133)$, all complications $(p=0.121)$, operation time $(p=0.762)$, intraoperative blood loss $(p=0.753$ ), or surgical procedure (open $v s$. laparoscopy, $p=1.000)$.

The prognostic significance of the change in the PMI. The median follow-up period was 24.1 months among 47 patients. Twelve patients had recurrent disease, and six died from the recurrent disease. Among the patients who showed a $>10 \%$ decrease in their PMI, six died from the recurrent disease $(40 \%)$. However, no patients died of RC $(0 \%)$ among the patients whose PMI values did not decrease by $>10 \%$. A $>10 \%$ decrease in the PMI value was associated with a shorter OS compared to patients whose PMI values did not show a $>10 \%$ decrease (Figure 2). Among the patients who showed a $>10 \%$ decrease in their PMI, recurrent disease was observed in seven patients (47\%). In 
Table III. Univariate and multivariate analysis with respect to relapse-free survival with rectal cancer.

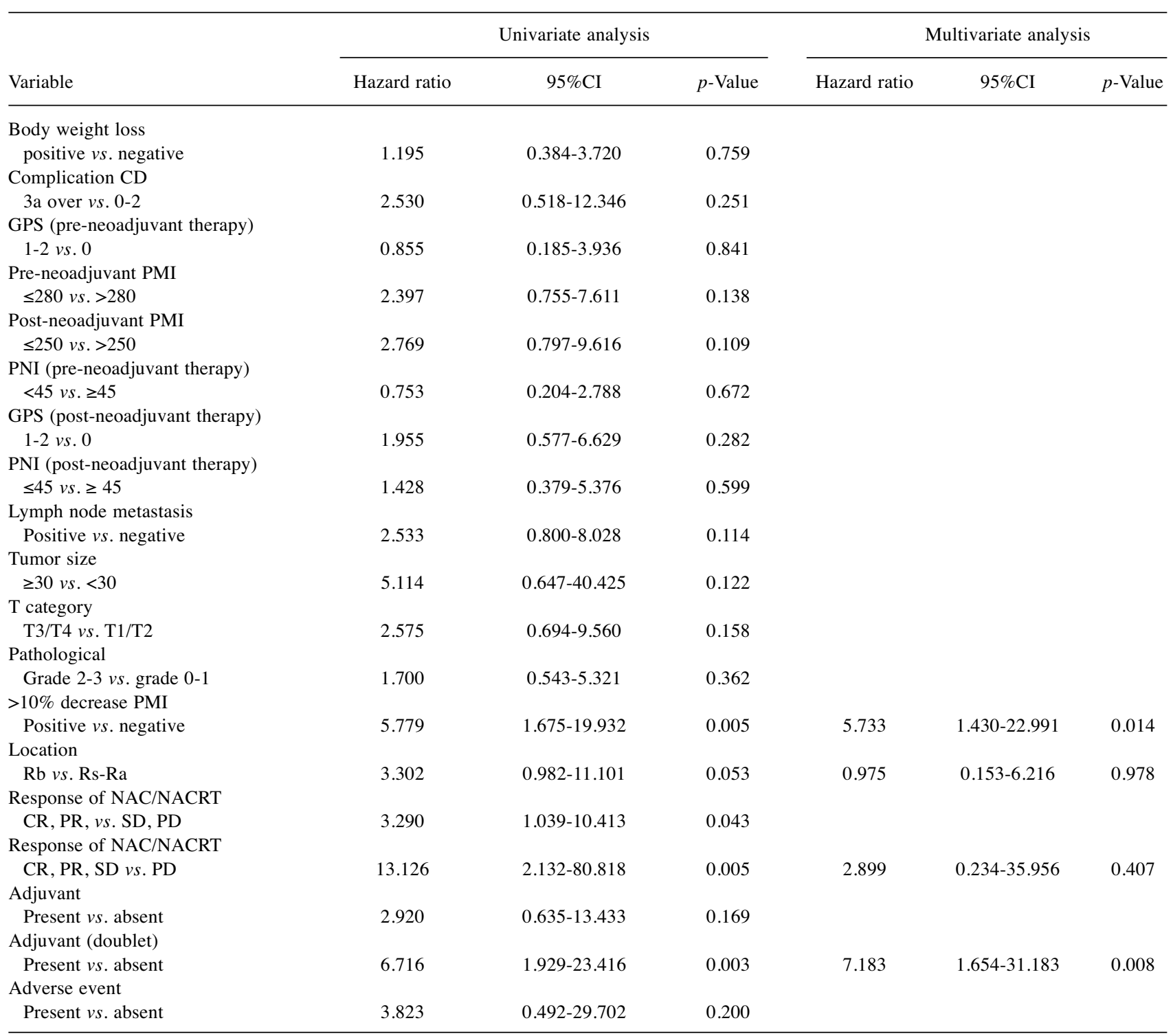

contrast, five patients had recurrent RC (16\%) among those whose PMI values did not decrease by $>10 \%$. A $>10 \%$ decrease in the PMI value was associated with a shorter RFS than in the patients whose PMI values did not show a $>10 \%$ decrease (Figure 3).

The univariate analyses revealed that a $>10 \%$ decrease in the PMI and response of neoadjuvant therapy and adjuvant therapy of doublet chemotherapy was significantly associated with RFS $(p=0.005)$. However, neither the pre- nor post-PMI were associated with RFS $(p=0.138, p=0.109)$. In the multivariate analysis, a $>10 \%$ decrease in the PMI and adjuvant therapy of doublet chemotherapy were independently associated with RFS (Table III).

\section{Discussion}

Neoadjuvant therapy has recently been established as a standard treatment for locally advanced RC. However, even if patients are able to tolerate chemotherapy and surgery for $\mathrm{RC}$, the disease may recur. Thus, predicting the risk of recurrence is very important for predicting prognosis after surgery.

In the present study, we investigated the correlation between the prognosis of RC and the change in the PMI after neoadjuvant therapy. The PMI before and after neoadjuvant therapy was not associated with prognosis or postoperative complications. However, the decrease in the PMI during 
neoadjuvant therapy was associated with postoperative severe complications and a poor RFS and OS.

Sarcopenia is defined as a syndrome characterized by the progressive and systemic loss of skeletal muscle mass and muscular strength (19). Cancer patients are particularly likely to develop sarcopenia because of the catabolic change in proteins caused by excessive inflammatory reactions and their poor nutrition status, due to hypermetabolism and appetite loss. Thus, the association between sarcopenia and cancer has recently received a great deal of attention. Previous studies have shown that sarcopenia is associated with postoperative complications and a poor prognosis in various carcinomas (5$7,20-22)$. However, other studies have reported conflicting results (23). Our study showed that there was no relationship between the individual PMI values before and after neoadjuvant therapy and the post-operative complications and prognosis. This result suggests the potential importance of catabolic changes and poor nutrition during neoadjuvant therapy. Indeed, Reisinger et al. reported that a loss of muscle mass during NACRT was associated with postoperative mortality in patients with esophageal malignancies $(24,25)$.

Patients with a decreased PMI during neoadjuvant therapy are thought to be more likely to develop post-operative severe complications and recurrence than those without such a decrease. Our study showed that preventing a decrease in the PMI helps prevent post-operative complications. It is important to prevent muscle weakness and maintain and improve the nourishment state during neoadjuvant therapy. Specifically, physical exercise and nutritional support may preserve the muscle mass during neoadjuvant therapy. These patients may also need to undergo aggressive adjuvant chemotherapy and receive detailed follow-up.

The present study was associated with certain limitations. First, it was a retrospective study with a short follow-up period and was performed at a single institution with a small number of patients. Second, data on the contents and quantity of the patients' meals and the calories consumed per day during neoadjuvant therapy were not collected. We also focused on the PMI, but other methods of evaluating the muscle mass, such as a bioelectrical impedance analysis were not used because this study was a retrospective study. Third, although we set $10 \%$ as the cut-off value in the current study based on the ROC curve findings, the appropriate cut-off value for the decrease in the PMI differed from the values mentioned in previous studies. Larger-scale prospective studies should therefore be performed in order to confirm our findings.

In conclusion, a decrease in the PMI during neoadjuvant therapy was an independent negative prognostic factor for locally advanced RC patients undergoing neoadjuvant therapy. Further prospective studies are needed to confirm the clinical effects of these differences. Finally, nutritional intervention with an elemental diet and physical exercise is required for RC patients undergoing neoadjuvant therapy.

\section{Conflicts of Interest}

There are no financial or other interests with regard to the submitted manuscript that might be construed as a conflict of interest.

\section{Authors' Contributions}

Tatsunari Fukuoka designed the study, performed the statistical analysis and draft the manuscript; Kiyoshi Maeda designed the study, performed the statistical analysis and draft the manuscript; Hisashi Nagahara collected the clinical data and revised the manuscript critically; Masatsune Shibutani collected the clinical data and revised the manuscript critically; Yasuhito Iseki collected the clinical data and revised the manuscript critically; Shinji Matsutani collected the clinical data and revised the manuscript critically; Kosei Hirakawa designed the study and critically reviewed the manuscript; Masaichi Ohira designed the study and critically reviewed the manuscript.

\section{References}

1 Hori M MT, Shibata A, Katanoda K, Sobue T, Nishimoto H and Japan Cancer Surveillance Research Group: Cancer incidence and incidence rates in japan in 2009: A study of 32 populationbased cancer registries for the monitoring of cancer incidence in japan (mcij) project. Jpn J Clin Oncol 45(9): 884-891, 2015. PMID: 26142437. DOI: 10.1093/jjco/hyv088

2 Sauer R, Liersch T, Merkel S, Fietkau R, Hohenberger W, Hess C, Becker H, Raab HR, Villanueva MT, Witzigmann H, Wittekind C, Beissbarth T and Rodel C: Preoperative versus postoperative chemoradiotherapy for locally advanced rectal cancer: Results of the german cao/aro/aio-94 randomized phase iii trial after a median follow-up of 11 years. J Clin Oncol 30(16): 1926-1933, 2012. PMID: 22529255. DOI: 10.1200/ JCO.2011.40.1836

3 Sebag-Montefiore D, Glynne-Jones R, Falk S, Meadows HM and Maughan T: A phase I/II study of oxaliplatin when added to 5-fluorouracil and leucovorin and pelvic radiation in locally advanced rectal cancer: A colorectal clinical oncology group (ccog) study. Br J Cancer 93(9): 993-998, 2005. PMID: 16249791. DOI: $10.1038 /$ sj.bjc.6602818

4 Matsumoto T, Hasegawa S, Zaima M, Inoue N and Sakai Y: Outcomes of neoadjuvant chemotherapy without radiation for rectal cancer. Dig Surg 32(4): 275-283, 2015. PMID: 26113223. DOI: $10.1159 / 000430469$

5 Okumura S, Kaido T, Hamaguchi Y, Fujimoto Y, Masui T, Mizumoto M, Hammad A, Mori A, Takaori K and Uemoto S: Impact of preoperative quality as well as quantity of skeletal muscle on survival after resection of pancreatic cancer. Surgery 157(6): 1088-1098, 2015. PMID: 25799468. DOI: 10.1016/ j.surg.2015.02.002

6 Harimoto N, Shirabe K, Yamashita YI, Ikegami T, Yoshizumi T, Soejima Y, Ikeda T, Maehara Y, Nishie A and Yamanaka T: Sarcopenia as a predictor of prognosis in patients following hepatectomy for hepatocellular carcinoma. Br J Surg 100(11): 1523-1530, 2013. PMID: 24037576. DOI: 10.1002/bjs.9258

7 Huang DD, Zhou CJ, Wang SL, Mao ST, Zhou XY, Lou N, Zhang Z, Yu Z, Shen X and Zhuang CL: Impact of different sarcopenia stages on the postoperative outcomes after radical 
gastrectomy for gastric cancer. Surgery 161(3): 680-693, 2017. PMID: 27712873. DOI: 10.1016/j.surg.2016.08.030

8 Psutka SP, Carrasco A, Schmit GD, Moynagh MR, Boorjian SA, Frank I, Stewart SB, Thapa P, Tarrell RF, Cheville JC and Tollefson MK: Sarcopenia in patients with bladder cancer undergoing radical cystectomy: Impact on cancer-specific and all-cause mortality. Cancer 120(18): 2910-2918, 2014. PMID: 24840856. DOI: $10.1002 /$ cncr.28798

9 Sakurai K, Kubo N, Tamura T, Toyokawa T, Amano R, Tanaka H, Muguruma K, Yashiro M, Maeda K, Hirakawa K and Ohira $\mathrm{M}$ : Adverse effects of low preoperative skeletal muscle mass in patients undergoing gastrectomy for gastric cancer. Ann Surg Oncol 24(9): 2712-2719, 2017. PMID: 28477088. DOI: 10.1245/s10434-017-5875-6

10 Miyamoto Y, Baba Y, Sakamoto Y, Ohuchi M, Tokunaga R, Kurashige J, Hiyoshi Y, Iwagami S, Yoshida N, Watanabe M and Baba H: Negative impact of skeletal muscle loss after systemic chemotherapy in patients with unresectable colorectal cancer. PLoS One 10(6): e0129742, 2015. PMID: 26069972. DOI: 10.1371/journal.pone. 0129742

11 Gerard JP, Conroy T, Bonnetain F, Bouche O, Chapet O, ClosonDejardin MT, Untereiner M, Leduc B, Francois E, Maurel J, Seitz JF, Buecher B, Mackiewicz R, Ducreux M and Bedenne L: Preoperative radiotherapy with or without concurrent fluorouracil and leucovorin in T3-4 rectal cancers: Results of FFCD 9203. J Clin Oncol 24(28): 4620-4625, 2006. PMID: 17008704. DOI: $10.1200 / J C O .2006 .06 .7629$

12 Bosset JF, Collette L, Calais G, Mineur L, Maingon P, RadosevicJelic L, Daban A, Bardet E, Beny A, Ollier JC and EORTC Radiotherapy Group Trial 22921: Chemotherapy with preoperative radiotherapy in rectal cancer. N Engl J Med 355(11): 1114-1123, 2006. PMID: 16971718. DOI: 10.1056/NEJMoa060829

13 Sobin LH, Gospodarowicz MK, Wittekind C and International Union against Cancer: Tnm classification of malignant tumours. 7th edn. Wiley-Blackwell: Chichester, West Sussex, UK; Hoboken, NJ, 2010.

14 Japanese Society for Cancer of the Colon and Rectum: Japanese classification of the colorectal carcinoma 8th japanese edition. Kanehara, 2014.

15 Dindo D, Demartines $\mathrm{N}$ and Clavien PA: Classification of surgical complications: A new proposal with evaluation in a cohort of 6336 patients and results of a survey. Ann Surg 240(2): 205-213, 2004. PMID: 15273542. DOI: 10.1097/01.sla.000 0133083.54934.ae

16 Salerno G, Sinnatamby C, Branagan G, Daniels IR, Heald RJ and Moran BJ: Defining the rectum: Surgically, radiologically and anatomically. Colorectal Dis 8(Suppl 3): 5-9, 2006. PMID: 16813584. DOI: $10.1111 /$ j.1463-1318.2006.01062.x

17 Kenig J and Richter P: Definition of the rectum and level of the peritoneal reflection - still a matter of debate? Wideochir Inne Tech Maloinwazyjne 8(3): 183-186, 2013. PMID: 24130630 DOI: $10.5114 /$ wiitm.2011.34205
18 Eisenhauer EA, Therasse P, Bogaerts J, Schwartz LH, Sargent D, Ford R, Dancey J, Arbuck S, Gwyther S, Mooney M, Rubinstein L, Shankar L, Dodd L, Kaplan R, Lacombe D and Verweij J: New response evaluation criteria in solid tumours: Revised recist guideline (version 1.1). Eur J Cancer 45(2): 228247, 2009. PMID: 19097774. DOI: 10.1016/j.ejca.2008.10.026

19 Cruz-Jentoft AJ, Baeyens JP, Bauer JM, Boirie Y, Cederholm T, Landi F, Martin FC, Michel JP, Rolland Y, Schneider SM, Topinkova E, Vandewoude M, Zamboni M and European Working Group on Sarcopenia in Older People: Sarcopenia: European consensus on definition and diagnosis: Report of the european working group on sarcopenia in older people. Age Ageing 39(4): 412-423, 2010. PMID: 20392703. DOI: 10.1093/ageing/afq034

20 Takagi K, Yoshida R, Yagi T, Umeda Y, Nobuoka D, Kuise T and Fujiwara T: Radiographic sarcopenia predicts postoperative infectious complications in patients undergoing pancreaticoduodenectomy. BMC Surg 17(1): 64, 2017. PMID: 28549466. DOI: $10.1186 / \mathrm{s} 12893-017-0261-7$

21 Lieffers JR, Bathe OF, Fassbender K, Winget M and Baracos VE: Sarcopenia is associated with postoperative infection and delayed recovery from colorectal cancer resection surgery. Br J Cancer 107(6): 931-936, 2012. PMID: 22871883. DOI: 10.1038/ bjc. 2012.350

22 Valero V, 3rd, Amini N, Spolverato G, Weiss MJ, Hirose K, Dagher NN, Wolfgang CL, Cameron AA, Philosophe B, Kamel IR and Pawlik TM: Sarcopenia adversely impacts postoperative complications following resection or transplantation in patients with primary liver tumors. J Gastrointest Surg 19(2): 272-281, 2015. PMID: 25389056. DOI: 10.1007/s11605-014-2680-4

23 Grotenhuis BA, Shapiro J, van Adrichem S, de Vries M, Koek M, Wijnhoven BP and van Lanschot JJ: Sarcopenia/muscle mass is not a prognostic factor for short- and long-term outcome after esophagectomy for cancer. World J Surg 40(11): 2698-2704, 2016. PMID: 27272482. DOI: 10.1007/s00268-016-3603-1

24 Reisinger KW, Bosmans JW, Uittenbogaart M, Alsoumali A, Poeze M, Sosef MN and Derikx JP: Loss of skeletal muscle mass during neoadjuvant chemoradiotherapy predicts postoperative mortality in esophageal cancer surgery. Ann Surg Oncol 22(13): 4445-4452, 2015. PMID: 25893413. DOI: 10.1245/s 10434-015-4558-4

25 Collins J, Noble S, Chester J, Coles B and Byrne A: The assessment and impact of sarcopenia in lung cancer: A systematic literature review. BMJ Open 4(1): e003697, 2014. PMID: 24384894. DOI: 10.1136/bmjopen-2013-003697
Received July 6, 2019

Revised July 14, 2019

Accepted July 15, 2019 